\title{
The Semiotics of Symbols in Tennyson's the Eagle and Al Aqad's Al Okab: a Comparative Study
}

\author{
Dr. Walid Abu Nada \\ Associate Prof. of Arabic Criticism at Islamic University of Gaza
}

\section{Dr. Akram Habeeb}

Assistant Prof. of English Literature and Criticism at the Islamic University

\begin{abstract}
This paper is a comparative study which focuses on two poems having almost the same title. One was written by the famous Victorian poet, Lord Alfred Tennyson, entitled The Eagle Fragment. The other was written by the well acclaimed Arab critic and poet, Mamoud Abbas Al Aqad entitled, Al Okab Al Harem, the Old Eagle. The study of the two poems was focusing on the semiotics of the symbol in the two poems. In other words, the paper is an attempt to decode the signs and the symbols by using the methodology developed by structuralism, an approach of reading which has been enunciated by De Saussure. The approach which depends on the relationship between the signifier and the signified was employed in this comparative study to show how each was either sharing or contradicting the other. The paper starts by literature review and definition of terms. Hence, interpretation of the title, the content and the poetic experience of each poet was conducted in comparative content.
\end{abstract}

Keywords: Tennyson's the eagle, Al Aqad Al Okab Al Harem, Comparative study, The semiotics of symbols.

\section{INTRODUCTION}

Regardless of cultural multiplicity and diversity in literary traditions; writers all over the world are usually involved in a give and take - relationship; they either draw on each other's or get impacted by writers who do not necessarily share the same culture but rather the same experience. Working on this assumption, the purpose of this paper is to conduct a comparative analysis of the central symbol in two poems having almost the same title: The first one is the Eagle which was written by the Victorian poet Alfred Tennyson (1885) and the second, Al Okab Al Harem, the Old Eagle written by Abass Mahmoud Al Aqad. The study will investigate the semiotics of the symbols in the two poems, thus coming up with analytical reading strategies which are based on decoding the symbols in both texts in a way which will reveal how Al Aqad was influenced by the late Victorian poet Alfred Tennyson. The latter looks at the eagle as a source of power, majesty and challenge, yet the former looks at the eagle as a vulnerable bird that has become old, invalid and dysfunctional. This paper will attempt to decode the signs and the symbols by using the methodology developed by structuralism, an approach of reading which has been enunciated by the Swiss philosopher and thinker, Ferdinand de Saussure (1857-1913) whose ideas about language are vital in understanding signs and symbols (De Saussure 2011).

\section{Definitions of Terms AND THE EMERgent ANALYTICAL APPROACH}

It is indispensible if not imperative that we, and before we embark on analyzing the two texts, build a theoretical context which will familiarize readers with certain concepts and terms used by structuralists mainly Ferdinand de Saussure. Indeed Saussure is considered as the first theorist of semiotics in Europe. His ideas have already laid the foundations of what is broadly called today as semiology. He posits that language is made up of Langue and Parole. Saussure classifies langue into two categories: individual and collective. (De Saussure 1985: p.26) The two terms, semiotics and semiology seem to name two different terms, yet the two terms are interchangeable. However, the European critics represented by De Saussure prefer to classify it as Semiotics, whereas the Americans refer to the same term as semiology. To avoid confusing the two terms, the Arabic critic and scholar Salah Fadel suggests that we stick to the term semiology (Fadel 1998. P 297). Semiology as such is an analytical approach which focuses on interpreting the signs whether verbal or non verbal. Each 
sign according to Saussure falls into two parts: the signifier and the signified. Some signs as argued by Hamdawai are non verbal, yet transcendental signifiers that are usually emerge in a given culture (Hamdawi. 2010. P.4). The most important definition is that of Saussure himself:

Language is a system of signs that express ideas, and is therefore comparable to a system of writing, the alphabet of deaf-mutes, military signals, etc. But it is the most important of all these systems. A science that studies the life of signs within society is conceivable it would be part of social psychology and consequently of general psychology; I shall call it semiology (from Greek, semeion "sign") Semiology would show what constitutes signs, what laws govern them. (p. 16)

Essam Kamel (2003. P.17) comments on this definition and goes on to describe language as a system of signs which is considered part of social psychology which he dubbed as Semiology. Al Ahmar (2010.p17) embraces the view of the renowned American critic who relates language to the general logic and asserts that semiotics is but another name for semiology. In spite of the fact that semiology is related to logic and semiotics has to do with analytical procedures, the two terms have theoretical as well as practical and analytic aspects. It is clear then that semiology seeks to investigate the sign and its significance which is open to multiple interpretations perhaps different from what the text wants to imply. Therefore, and according to Kamel (2003. P.74), the signified is open to interpretations and it is limited by fixed interpretation but the act of reading becomes a creative process where the reader is involved in an idiosyncratic act of interpretations. Given this freedom of reading the text and interpreting are relevant signs; it is hoped that our reading of the two texts, mentioned above, would be an act of creative reading and fruitful interpretation of the different signs and symbols inherent in the two poems.

The first sign we are going to focus on in our semiotic interpretation is the title. Indeed the title is a real point of entry to interpreting and understanding a given text. According to (Shakroos 2002) the title is a meeting point where the text, the author, and the reader are involved in a constructive relationship which will eventually determine the meaning of a given text. In this context, (Abed Al qader 2003 p.24) lists three important relationships: the semiotic, the structural, and the reflexive. In El Aqad's poem, Al Oqab Al Harem, The old Eagle, the title is chiefly made of the noun and the attributive adjective. In Arabic such use of structure creates a permanent affinity between the epithet and the noun described. ( Al Razzi,1981 p.2012/14). Al Okab, the eagle, is word which connotes several meanings. It indicates freedom, power, dignity, wildness, and high soaring. The Arabs used to dub eagles as the master of the birds, a master which is distinguished for its generosity and supremacy. It is also distinguished for its piercing looks and unique courage. Such cultural perception of the eagle has led to the emergence of frequently used expression in which the eagle is a framework of reference to any concept. An example of the expression is that an $\mathrm{X}$ has as piercing eye as that of the eagle. However, the use of the adjective "old" before the eagle has created a kind displacement to the different connotations which has been just mentioned. Now this eagle is old, vulnerable, invalid, is likely to perish at any moment. In Tennyson's the eagle, the title represents monumental creature that forever stands for dignity, power, and unique potentials of soaring high in the sky. It should be noticed that such meanings are not displaced but rather affirmed when we are led to think of the trapped persona. In such a comparison man, it is the poet rather than the eagle which is stripped out of all what the eagle stands for. In western culture the eagle is often associated with the creator' it always soars up and send message to heaven, unlike the Raven which always sends messages down to earth. (Spirits of the west coast. Online)

\section{SEMiology OF CONTENT}

Attention to content has been a major concern of Al Dewan School; these critics included Al Aqad, Almazni, Shoukry and Dasougi were as much concerned with content as they were in form. They believed that content is an important factor in the act of interpretation. Inasmuch as this paper is concerned with the content of tow poem: one was written by Tennyson and the other by Al Aqad. It is indispensible if not imperative to quote the two poems in full and juxtapose the Arabic with the English in order to conduct a kind of credible analysis. Here are the two poems:

The Eagle

He clasps the crag with crooked hands;

Close to the sun in lonely lands, 
Ring'd with the azure world, he stands.

The wrinkled sea beneath him crawls;

He watches from his mountain walls,

And like a thunderbolt he falls.

(Tennyson 1885)

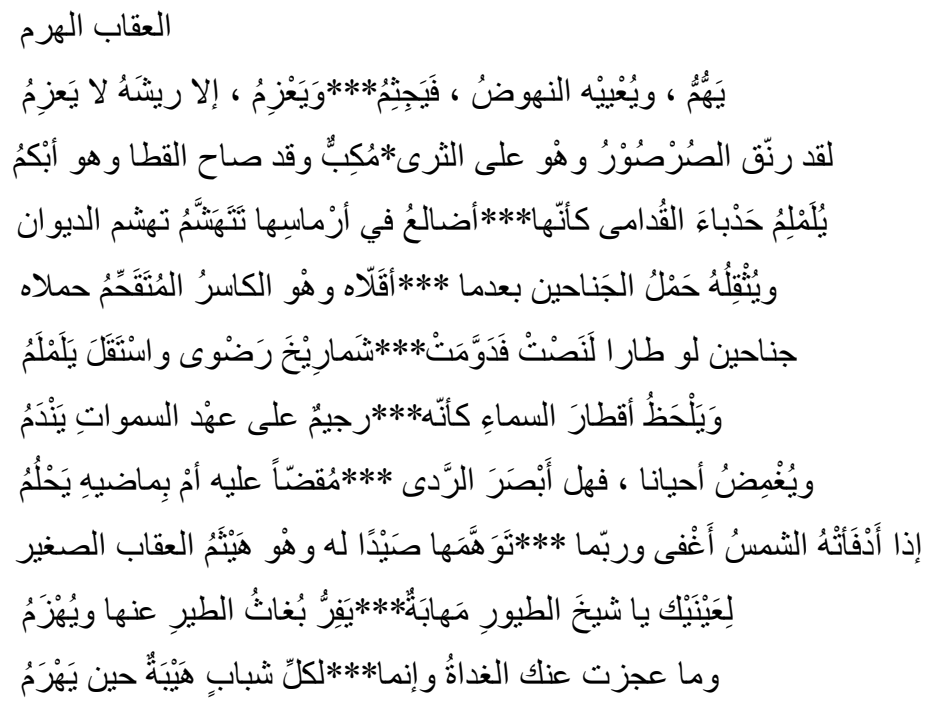

Al Aqad (1907)

In Tennyson's poem, "The Eagle" there is a wonderful image of a majestic eagle, a bird which has the ability to lift heavy objects off the ground, and then soars high in the sky. The image of the eagle becomes more fascinating when this eagle is viewed as a monarch who looks from the above at the wrinkled crawling sea as if it were a child crawling. This eagle has the power to go down in thunder storm fashion, thus filling the ground with panic and horror. However, Al Aqad's the Old Oqab, the elderly eagle, is very weak, unable to fly. It seems that life hardships rendered him very wreck, unable to rise above the ground. He tries to rise and fly' yet his wings fail him. These wings are becoming so weak to the extent that they cannot propel the flight of this eagle that used to soar high above the mountains. The irony is that the little creatures this eagle used to prey on are more powerful than this invalid eagle. In a very pensive mood this eagle closes its eyes and reflects on its past glory, supremacy, and dignity. The poet finally addresses the eagle in a tone full of sympathy, and then he concludes by suggesting the inevitability of recession in life. What is interesting in this comparison is the fact that the eagle is originally a symbol of power; in Tennyson's it is very powerful, majestic and glorious bird. Similarly in Al Aqad's poem the eagle stands for the same meanings only when the it was at the prime of its age.

\section{Fourth: Interplay of Signs, Signification, ANd ICONS in AlqAd's OKab ANd TENNYSON'S THE EAGLE}

A symbol along with its signification is considered an important area in the field of semiology. Al Fairouz Abadi (2008 p.669.) stresses this relationship between the sign and its meaning by his term "sign and signification". Semiotic critics almost agreed upon their definition of a symbol. Saussure thinks of a symbol in dual terms; he posits that language is made up of signs and each sign is made up of 'a signifier' and the signified. The symbolic relation between the signifier and the signified is arbitrary; yet natural; he thinks that the connotation of a given word of a given symbol cannot be replaced by the connotations of another; the relationship between the signifier and the signified is fixed. Fadel, (2012 p.83), also believes that the relationship between the signifier and the signified is monumental; he demonstrates that by using the word scale which always implies justice. Fadel adds that semiology lays the foundations of symbols and its various structural models. These symbols as suggested by Fadel are key communication factors.

In his description of the old Aqab, Al Aqad was very innovative; he started to go beyond the familiar poetic devices by having the eagle as a symbol of the poetic sublimity; a moment when a poet transcends the world of senses and repudiates the familiar tropes such as similes, metaphors, etc. (Al 
Hawi 1983) . According to Mandour 2010 p.55) symbolism is a means whereby the poet expresses an intricate deep state of mind, and this is made possible because of our ability of using the language and creating relevant images to our experiences. Indeed Al Aqad has used that powerful bird as symbol of unique power which will unfortunately come to an inevitable end, thus suggesting that nothing remains young, powerful because the norm of inevitable deterioration is a must. To reflect such a sense of change, Al Aqad employed a number of antithetical attributes associated with the central symbol. The bird is wild, strong, dignified; all of these can be felt by the abruptness of the eagle and its ability to snatch its prey, it is an image which really demonstrates the horror caused by this wild bird which is considered the master of the skies. Looking deep into the poem would help the reader identify the central symbol and its relevant connotations. It is clear from the context of the poem that this eagle stands for the poet himself; the poet correlates his early days with the powerful young eagle. It was then the poet was full of passion and stamina for creation; yet at his old age, it lacks the vigor and the ability to write even though he has the will and the alacrity to write. This image is clear in the following lines where the eagle is slouching itself, yet its power fails him. So it stays on the ground unable to fly.

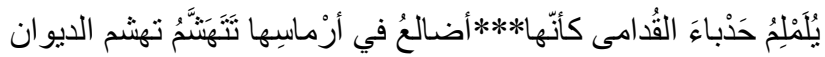

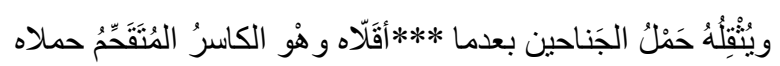

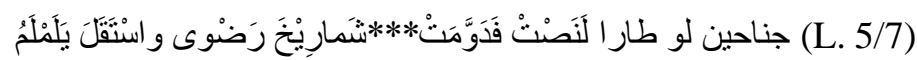

In the Tennyson"s the eagle we have unique juxtaposition where the entrapped poet envies the eagle for his power to soar high in the sky and comes down like thunderstorm.

He watches from his mountain walls,

And like a thunderbolt he falls (L.5/6)

Contrary to Al Aqad, Tennyson sees in the eagle what the poet lacks; he cannot leave off the ground, while the eagle can soar high in the sky and watches from the mountain walls, and then falls like a thunderbolt. Evidently Tennyson's eagle stands for transcendental abilities which the poet unfortunately is denied of. In Al aqad, the image of the weak, yet dignified and resilient eagle is

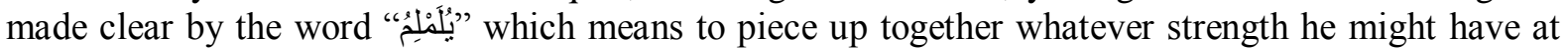
this old age. This image which is linked with the central symbol is indicative of the poet's vulnerability and inability to exercise his past glory as hinted in the following lines:

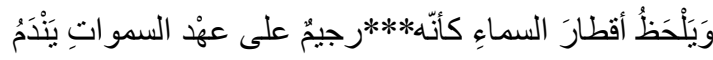

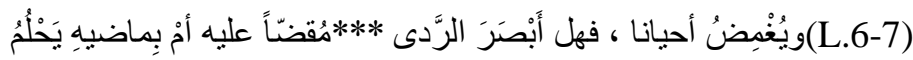

This intricately symbolic image is sustained when the poet keeps contrasting between the past and the present situation of the eagle. This eagle which used to boast of its keen and vigilant eyesight is no longer able open these eyes. This disparity leaves the poet with sense of agony and grief.

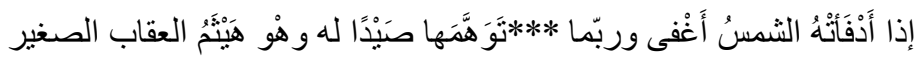

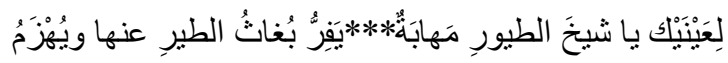

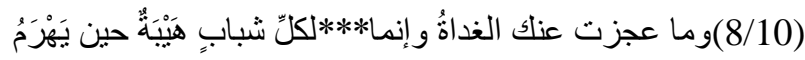

The poet continues to build this symbolic image inasmuch as straightforward images might not convey the sense of transformation the eagle has gone through. It is then; the poet gets more involved and identifies himself with this eagle. This has been experienced by more than one poet; for instance, the Arab Romantic poet Jobran (1994:419) refers to this situation by:

$$
\begin{aligned}
& \text { وَفَي الزَّر ازيرِ جُبنٌ وَهيَ طائرَةٌ }
\end{aligned}
$$

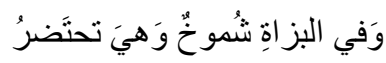

In this sense a symbol becomes a point of departure in the use of literary devices; it is a device by which the original connotations attached to a given symbol can be displaced and substituted by different implications. Accordingly, Al Aqad's eagle implicitly conveys meanings beyond the traditional meanings inherent in this symbol. From semiotic point view this eagle becomes indicative of codes situated in a given context (Shultz 1994.p86). The eagle becomes a figure which embraces deep antithetical meanings in a shape of binary opposites encoded by the same symbol of this eagle. A 
further semiological displacement effected by Al Aqad's eagle is the poet's use of this eagle as persona; it is persona which expresses the poet's feelings and experience. Thus this person gets conflated with the poet and the two become one. However, in a very clever way the poet kept distance from the eagle, yet in the final scene the poet shows much sympathy with the eagle and this has lead him to mix sympathy with admiration.

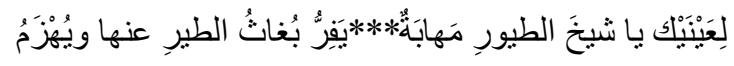

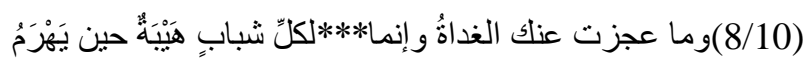

The poet looks at the eagle with the sense of pity while reflecting on its past glory, and at this point, we observe that the poet started to imply for the reader that eagle's inability to fly is to be equated with that of the poet; the poet thinks that change is inevitable and nothing remains as it is. Accordingly the eagle symbol becomes a timeless icon which stands for power that eventually comes to an end with aging. (Admir1977 p.5)

Similarly Tennyson's eagle is symbol which is linked with the poet's mystic experience. According to Sutherland (1968) "the fragment offers internal evidence that the poem is not only about an eagle but also about the quality of 'eagleness'... The word eagle conveyed certain impressions, memories, or ideas in Tennyson's subconscious mind.(p23). Tennyson seems to have conflict between his tendency to classism and his mystical experience. Thus the eagle becomes an evangelic image which the poet tries to suppress for his inability to piece up together the fragments of his poem In Memoriam which was writing at that time. Tennyson's was aspiring for the poetic 'eaglenss' which would bring harmony between his mystic experience and his bent for classicism.

\section{Semiology of Drama in Terms of Action, Time, And Content}

A symbol should not be looked at in isolation of its context because it acquires a textual relationship which endows it with further connotations mainly when it is conveyed in a very dramatic scene as seen in Al Aqad's poem. According to Tonji (1993.p 436/2) drama is always connected with a dramatic event involving action, conflict, and time. However, the relationship between poetry and drama is as old as history itself. Poetry is really the real world of drama. Ancient Greeks used poetry in their plays; even today most playwrights have recourse to poetry in order to create a dramatic sense relevant to the intended meaning (Abu Reda 1981). Most of the time the dramatic effect is conveyed through action verbs. If we look at El Aquad's poem again we find that most of the drama is enacted by action and no action verbs; these include the verbs: get read, ails, perch, intends, cry, break, regret, observe, close eyes, dream, escape, gets old etc. These and other verbs are employed by the poet in order to create a very dramatic atmosphere whereby conflict, the core of drama, is created. ( Abu Reda 1981 p. 12). Action created by the use of such verbs, along with drama, brings about the conflict the eagle experience; it is an internal conflict represented by the eagle's wish to fly and its

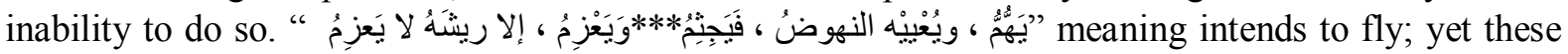
attempts wreck him and finally it cannot fly. Another aspect of this conflict is the eagle's struggle with the cruelty of time. It is a conflict which has always ends up by time devouring its prey (Hamouda 1982 p. 59). This intense conflict whether internal or external is conveyed by a moderate meter; this meter is known for its use in tragic situations. This meter is similar to the iambic meter which is often used in English poetry to convey a dramatic sense. This drama is also present in Tennyson's poem; the antithetical verbs of standing close to the sun, falling, crawling, and falling like thunderbolt. All these create a dramatic image in which the eagle emerges as an icon creature that can go beyond all barriers that might stand in its way. As late Victorian poet, Tennyson felt bitterness and sense of entrapment and clearly he was envious of this bird for its ability to transcend the nightmarish reality which was caused by the scientific and the philosophical investigations of that time. These investigations have left the Victorian mind in much ennui and confusion.

To conclude, it is very important to stress the fact that in spite of cultural differences and linguistic utterances, symbols and signs function on the same norms where a signifier might hint to specific fixed signifieds. However, the act of interpreting these signified should be an area where signification emerges to resonate with the personal experience of the author, the cultural values, and semiology of the words. 


\section{REFERENCES}

Abu Al Reda, Saed (1988) Al Kalema Wal Bena'a Aldrami. Cairo: Dar Al fikr Al Arabi. Al Aqad, Abass Mahmoud (1971) Diwan Al Aqad( first volume) Beirut: Al Asria.

Al Ahmar, Faisal ( 2010) Mojam Al Semiyaat. Beruit: Al Dar Alrabea Publisher.

Al Fairouz Abadi, Majed Al Deen (2008) Al Qamous Al Moheet. Ed. Al Shami, Anas. Cairo: Dar Al Hadeeth Publisher

Al Hawi, Ellia (1983) Al Ramaz Wal Serialia in Al sh'er Al Arabi and Al Gharbi. Beirut: Dar Al Sakafa publisher.

Al Tazi, Al Fakher( 1981) Al Tafsser Al Kabeer. Beruit : Dar Al Fiker Publisher.

Al Tonji( Mahmoud) (1993) Al Mojama Al Mofasal fi AlAdab. Beruit. Dar Al Kotob Al Elmia Publisher.

De Saussure, F. (2011). Course in General Linguistics [1916]. New York, NY: Columbia University Press. Retrieved from https://google scholar.com/scholar?hl=ar\&q=Ferdinand+de+Saussure.

De Sassure Ferdinand, (1985) Elm Al Logha Al Mokaran. Trans.Aziz, Younile. Baghdad: Dar Afak Arabia.

Fadel, Salah ( 2012) Manahej Al Nked Al Moaasser. Cairo: Atlas Publising

Fadel, Salah ( 1998) Nazaria Al Benayea fi Al Nakd Al Adabi. Cairo; Dar Al shourk Publishing House.

Hamoudi, Abed Al Aziz ( 1982) Al Bina Al Drami. Cairo: Anglo Egyptian.

Jubran, Khalil (1994) Al Majmoua'a Al Arabia. Beirut: Dar Al Jeel Publisher.

Kamel , Essam(2003) Al Etejah Asemiology wa nakd Al shaer. Cairo: Farah publisher.

Mandour Mohamad(2010) Al Adab Wa Mazahbo. Cairo: Dar Al Nhadha Publisher.

Ricks, C. (2014). Tennyson: A Selected Edition. London: Rutledge. Retrieved from https://books.google.ps/books?hl=ar\&lr=\&id=CiAwAAQBAJ\&oi=fnd\&pg=PP1\&dq=eagle+ten nyson

Spirits of the West Coast Native Gallery. Retrieved from ttps://spiritsofthewestcoast.com/

Shaqrous, Shadia (2002) Semiotics of the Title in Maqam Al Bouh of the poet Abdalla Al Ashi. Baskra: Algeria. Mohamad Kaider University press.

Shultz, Robert (1994) Semia and Taweel. Trns. Aziz, Yousef. Baghdad. Dar Afak Arabia Publisher.

Syran Minstry of Culture (1977) Semia Brag Le Al Masrah : Derassat Semiaea . Trans. Admir, Korea.

Sutherland, R. C. (1968). The" St. John Sense" Underlying" The Eagle: A Fragment" by Tennyson-" To Whom the Vision Came". Studies in the Literary Imagination, 1(1).

Tennyson, Alfred Lord (1885). The Eagle Fragment. Retrieved from http:// www. poetry foundation.org/poems-and-poets/poems/detail/45322. 